\title{
HERRAMIENTAS PROYECTUALES \\ EN LA OBRA DE ANNE TERESA \\ DE KEERSMAEKER. PROYECTO \\ COREOGRÁFICO Y PROYECTO \\ ARQUITECTÓNICO: PARALELISMOS
}

\section{Marta Llorente Pascual}

Universidad Politécnica de Madrid, Escuela Técnica Superior de Arquitectura de Madrid (ETSAM)

\section{Resumen}

En este ensayo, se pretende establecer una articulación teórica entre el proyecto coreográfico y el proyecto arquitectónico, mostrando paralelismos a la hora de crear en ambos campos. A través del análisis coreográfico de varias piezas de la obra de Anne Teresa De Keersmaeker $(A T D K)$, se definen ciertas herramientas proyectuales como elementos configuradores de su creación artística. Se trata de conceptos como el "dibujo", la "estructura", la "repetición" y el "ritmo", los cuales constituyen estrategias coreográficas extrapolables al contexto arquitectónico. De esta manera se plantean nuevas correspondencias entre los dos ámbitos. En definitiva, se trata de similitudes conceptuales que nos pueden ser muy útiles para la creación y el entendimiento de una u otra disciplina y que enriquecen la lectura de las obras.

\section{Palabras clave: DE KEERSMAEKER, ANNE TERESA; HERRAMIENTAS PROYEC- TUALES; PROYECTO COREOGRÁFICO; PROYECTO ARQUITECTÓ- NICO; PARALELISMOS; CREACIÓN ARTÍSTICA}

\section{Abstract}

This essay attempts to establish a theoretical relationship between the choreographic project and the architectural project, pointing out similarities when creating in both disciplines. Through the choreographic analysis of several pieces of Anne Teresa De Keersmaeker's work, certain design tools will be defined as fundamental elements of her artistic creation. Concepts such as "drawing", "structure", "repetition" and "rhythm", that constitute choreographic strategies and are also used in the architectonical context. Therefore new connections between both fields are suggested. In short, it refers to conceptual parallelisms that can be very useful when creating or understanding one discipline or the other and they help us interpreting the works.

\section{Keywords: DE KEERSMAEKER, ANNE TERESA; DESIGN TOOLS; CHOREO- GRAPHIC PROJECT; ARCHITECTURAL PROJECT; SIMILARITIES; ARTISTIC CREATION}

\footnotetext{
Llorente Pascual, Marta. 2015. "Herramientas proyectuales en la obra de ATDK. proyecto coreográfico y proyecto arquitectónico: paralelismos”. AusArt 3 (1): 91-117. D0I: 10.1387/ausart.14534
}

\section{AUSART}




\section{INTRODUCCIÓN}

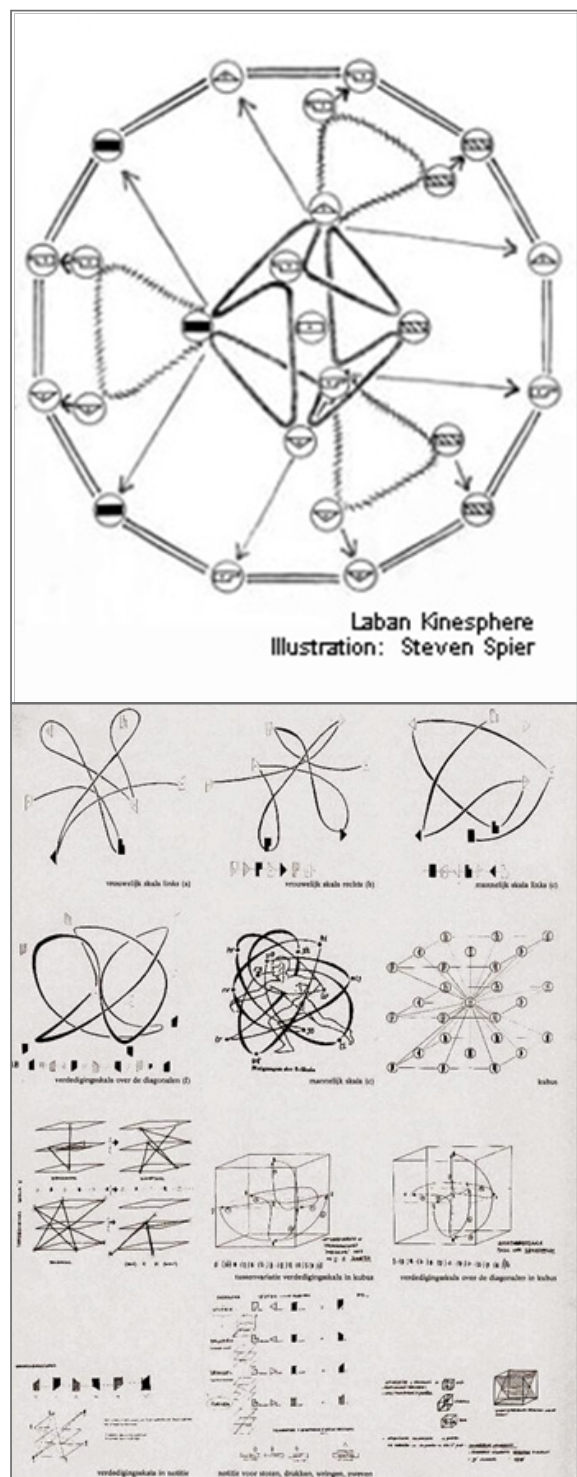

Fig. 1. Kinesfera vista en planta, direcciones y símbolos de Labanotación. Coréutica. Orientación espacial, planos, Labanotación. R.von Laban 20-30s.
"Es probable que la danza y la arquitectura sean las artes principales del hombre, de donde salen las otras artes". Con estas palabras expresa Rudolf von Laban en su Choreutics (1966) la estrecha y especial relación entre estas dos disciplinas que configuran el eje central de su investigación vital. Este coreógrafo húngaro desarrolla toda una teoría en torno al espacio, el movimiento, la geometría y una forma de expresarlo gráficamente a través de la Labanotación (fig. 1). Del mismo modo que Laban, son muchos los arquitectos y coreógrafos que a lo largo de la historia se han ocupado con estos temas, moviéndose en un campo de diálogo e intercambio de disciplinas. Por ejemplo el interés de Le Corbusier por el movimiento y la relación del cuerpo y sus proporciones con el espacio, le hace llegar a definir el "Modulor" como herramienta de medida humana y matemática (fig. 2), o su famosa "promenade Architecturale" que propone en muchos de sus edificios. Otros como F. Kiesler que desde una búsqueda fenomenológica llega a resultados como la "Endless House". Si bien es cierto que la danza y la arquitectura han ido de la mano desde tiempos antiguos, hasta el punto de poderlas considerar inseparables, no obstante encarnan valores polares: lo efímero y lo eterno. Por una parte el movimiento y por otra la quietud, sin embargo los nexos y la complicidad entre ambas nunca desaparecerán. Flujos entre terrenos fronterizos que se interconectan y muestran una gran complementariedad y casi una mutua dependencia para existir, de hecho tal y como Kant plantea, "el movimiento es la dimensión empírica del espacio, lo que le hace experimentable" ( [1781] 2011). 
Será a principios del siglo $\mathrm{XX}$ cuando esta estrecha relación que ha pasado por estados de mayor o menor contacto, reaparezca de forma más evidente y rotunda. En un primer momento a través de las Vanguardias con su descontextualización del Arte, en segundo lugar gracias a varias figuras, como Isadora Duncan, O. Schlemmer, M. Wigman, K. Jooss, M. Graham o los casos ya mencionados por nombrar algunos. Posteriormente en las décadas $50-60$ y 70 se llega mucho más lejos, volviendo a la unión indisoluble de danza-espacio, con novedosas propuestas como las de M. Cunningham, T. Brown, A. Halprin, L. Childs, P. Bausch o S. Forti. De esta manera los vínculos permanecerán hasta llegar a nuestro siglo.

El espíritu interdisiciplinar pervive en la actualidad y son frecuentes los "tándem" coreógrafos-arquitectos, ejemplos como W. Forsythe y D. Liebesknid o las numerosas colaboraciones de F. Flamand con diversos arquitectos como Zaha Hadid, J. Nouvel, D. Perrault, R. Scoficio y E. Diller, T. Mayne...

Dentro del marco de relaciones y sinergias expuesto, este artículo centra su interés en las herramientas proyectuales en danza y sus paralelismos con el proyecto de arquitectura. Se definirán distintos mecanismos comunes a los dos campos a través del análisis de varias piezas de la obra coreográfica de Anne Teresa de Keersmaeker. Se ha elegido a esta artista por su manera tan particular de entender el espacio y "proyectar" danza, incluso podría decirse que se encuentra muy cercana de "coreografiar" arquitectura.

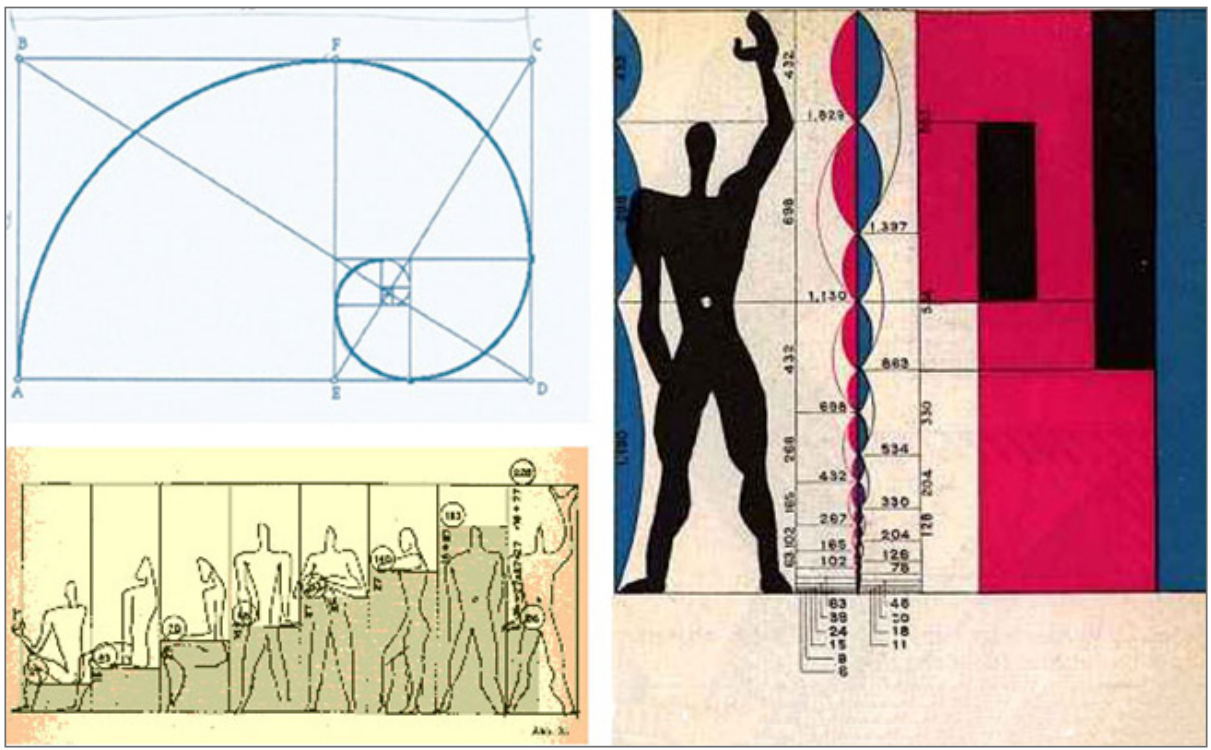

Fig. 2. Le Corbusier,"El Modulor" 


\section{CROQUIS DE UNA COREÓGRAFA: ANNE TERESA DE KEERSMAEKER}

"Danza es Arquitectura en movimiento. Danza es comunicación. Comunicación en la que se muestra nuestra relación con el mundo. La danza conecta energías entre el cielo y la tierra. Danza es una forma de expresar los sentimientos que el cuerpo lleva consigo". Esta es la definición de danza que nos da la artista flamenca ATDK, internacionalmente reconocida como la coreógrafa europea más destacada de la generación posterior a Pina Bausch (Kästner 2007). Efectivamente en la descripción encontramos muchos ecos del concepto de Danza que expuso Laban en su momento, y es que esta creadora tiene una manera de hacer muy arquitectónica y su método proyectual se acerca bastante al que muchos arquitectos utilizan. Desde los años 80 del S.XX, tras su formación con M. Béjart en MUDRA y en la University School of Arts en NY, ATDK no ha cesado de proponer e investigar en su medio de expresión por excelencia que es la danza; pero siempre desde una perspectiva de diálogo interdisciplinar que indudablemente incluye el espacio y la música.

Analizando detalladamente la anterior definición, confeccionaremos un croquis, extrayendo la esencia de lo que puede ser su proceso creativo, una imagen de conjunto y el espíritu de la obra que nos ocupa.

En primer lugar observamos que "la Danza es Arquitectura en movimiento", es decir los cuerpos son volúmenes arquitectónicos que se mueven por el espacio y van definiendo arquitecturas efímeras, que a su vez trasforman ese espacio inicial, no solo con sus diferentes trayectorias sino también con los movimientos de cada uno de sus miembros y con el nivel por el que transitan (nivel alto-verticalidad, medio-plano medio, nivel bajo-horizontalidad).

En este sentido, una forma de interpretar la danza como esculturas-arquitecturas generadas por el flujo de los cuerpos que está muy en concordancia con lo escrito por Deleuze sobre la obra de Bacon, en cuanto a la estructura y la figura: "El contorno parece muy simple, círculo u ovalo; es más bien su color lo que plantea problemas, en la doble relación dinámica en la que esta cogido. En efecto, el contorno como lugar es el lugar de un intercambio en los dos sentidos, entre la estructura material y la Figura, entre la Figura y el color plano. El contorno es como una membrana recorrida por un doble intercambio. Algo pasa en un sentido y en el otro... El movimiento va, más bien, de la estructura material, del color plano, a la Figura. En muchos cuadros, el color plano esta precisamente cogido en un movimiento por el cual forma un cilindro: se enrolla 
alrededor del contorno, del lugar; y envuelve, aprisiona a la Figura. La estructura material se enrolla alrededor del contorno para aprisionar la Figura que acompaña el movimiento de todas sus fuerzas" (Deleuze 1984, 10-1).

Efectivamente estos cuerpos al girar, andar, saltar y en ocasiones reforzados por sus sombras (en el caso de "Fase Four Movements to the music of Steve Reich"- fig.3) definen planos, superficies, membranas, volúmenes, en definitiva arquitecturas fugaces.

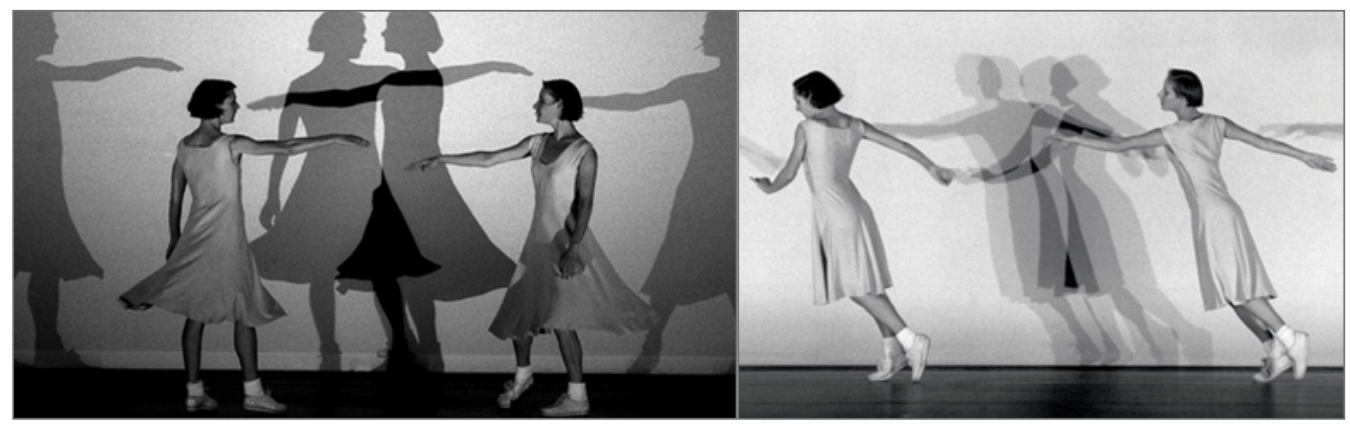

Fig. 3. Fase four movements to the music of S. Reich. (Piano Fase)

ATDK al igual que un buen arquitecto, concibe sus piezas sustentadas en una sólida estructura, que en ocasiones es narrativa y se apoya en la organización musical, en cierto modo trata de traducir la música espacialmente, grafiarla con los cuerpos desplazándose por el espacio; otras veces, este esqueleto es el puro armazón espacial, como si de una obra arquitectónica se tratase y que queda reflejado en el plano horizontal con un dibujo (trazado literalmente en el pavimento) y que servirá de partitura, posteriormente los bailarines darán vida a ese grafismo. Sobre estos cimientos que sirven de directrices y sustento, se construye corpus de gran complejidad del que se pueden desgranar múltiples herramientas proyectuales que posteriormente estudiaremos.

Una base correspondiendo a la configuración musical la encontramos en piezas como "Fase, four movements to the music of Steve Reich" (1982) o "Rosas danst Rosas" (1983) por nombrar alguna. En la primera el hilo conductor claramente es la música, como el propio título indica; dividida en cuatro movimientos se ilustran composiciones de S. Reich para distintos instrumentos (19661972) a través de tres duetos y un solo.

A su vez el esquema musical tiene otra subestructura y es correspondido espacialmente con claras configuraciones geométricas: el piano son líneas 
longitudinales que avanzan y se retiran del proscenio, las variaciones de voz de "Come out" se definen con dos puntos fijos en primer plano del escenario, los cuales contienen líneas circulares, rectas y diagonales, a continuación las cuerdas del violín dibujan un círculo con todas sus variaciones y por último "Clapping Music" se desplaza diagonalmente sobre un ritmo de palmas. En resumen líneas laterales, diagonales, puntos y un círculo explorado en todas sus facetas y diámetros. Círculo a modo de "rosetón" y que quizá sea la premonición del nombre que posteriormente llevará la compañía: "Rosas" (fig.4).

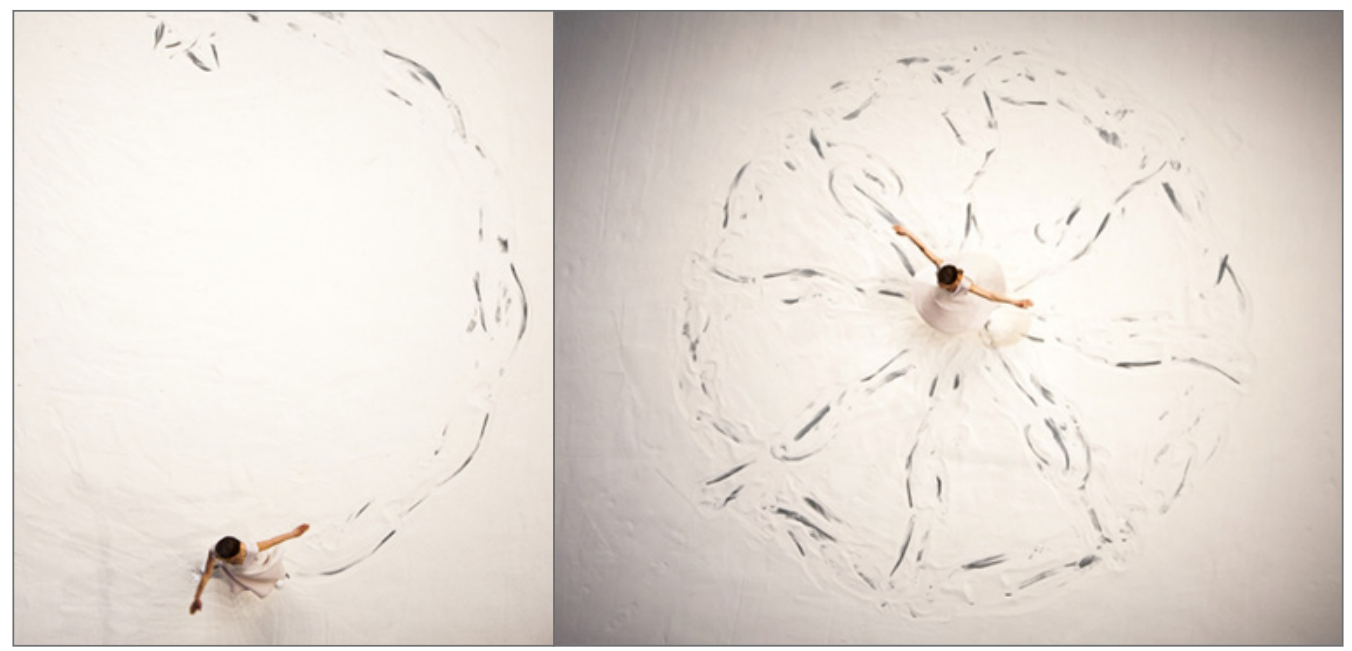

Fig. 4. Fase four movements to the music of S. Reich. (Violin Fase)

Otro ejemplo de fundamentación en la música lo constituye "Rosas danst Rosas", aunque en este caso concreto el proceso creativo fue en paralelo, es decir que música y danza van surgiendo a la par. Así se crea un marco dramatúrgico que guía el movimiento y la música, T. De Mey sugiere una estructura basada en el desarrollo de una jornada, con cuatro movimientos correspondientes a los diferentes momentos del día, precedidos de una introducción y cerrados por un coda. En esta pieza encontramos un tratamiento del "cronotopo"1 (espacio-tiempo) muy específico ya que cada parte presenta unas características espaciales, de afectos y de construcción acordes con un momento en el tiempo. Cada una de estas unidades se desarrolla con una geometría distinta (desplazamientos en el espacio) con una distribución de los bailarines heterogénea (cuarteto, dúos, trío, solo) y a un nivel en cuanto a la arquitectura corporal diferente (vertical, horizontal, plano medio). Igualmente cada entidad se caracteriza por un tipo de sonoridad y de sensación que responde a un momento concreto (fig.5). 


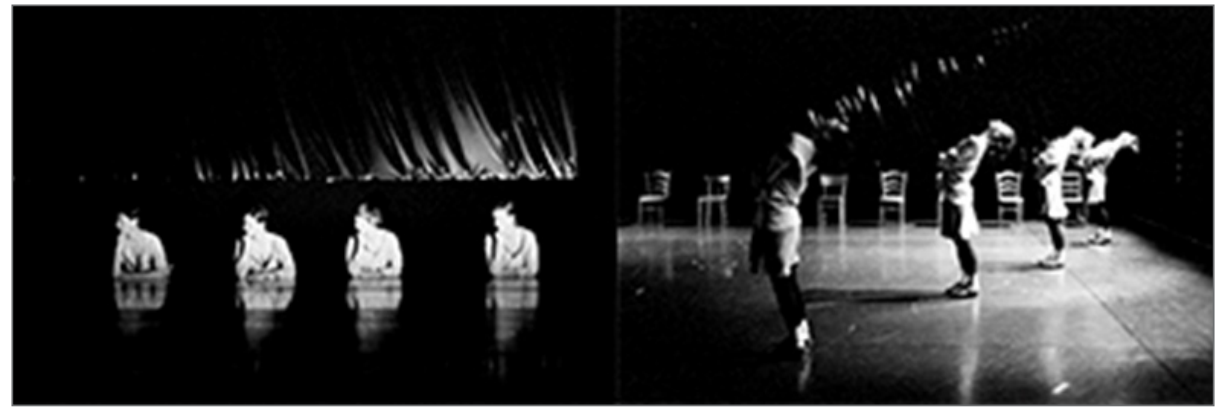

Fig. 5 Rosas danst Rosas 1983

Piezas en las que aparece, además del soporte musical de base (S.Reich), la partitura gráfica físicamente son por ejemplo "Drumming" (1998) o "Rain" (2001) en las cuales la geometría es una compleja trama a la que se suman múltiples capas y lecturas para tejer la pieza. Las líneas y trazados han pasado de estar virtualmente en el espacio a materializarse en el plano horizontal. (Figs. 6 y 7). Las distintas capas estructurales se van superponiendo, a la percusión de S. Reich se suman voces y el movimiento se organiza en torno a sus leyes y a las del dibujo. En muchas otras ocasiones los límites entre sistemas son difusos; ambos dialogan y se funden como en "Vortex Temporum" (2013) o en "Partita 2" (2013) y resulta menos obvio distinguir los códigos, aunque siguen estando patentes. Sobre esta última pieza, colaboración entre la coreógrafa y Boris Charmatz, para la que ATDK crea el marco arquitectónico y geométrico y sobre la que ella misma anota: "Para mí Bach es estructura, pero esta dimensión que transciende está escrita en el cuerpo"2.

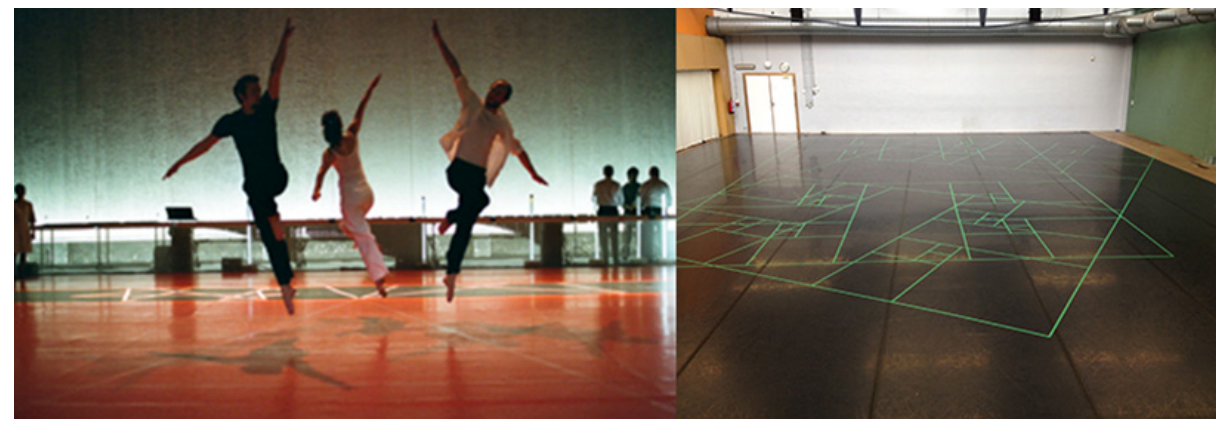

Fig. 6 Drumming 1998 . Dibujo.Partitura aula de ensayo P.A:R.T.S.

En segundo lugar, en su descripción ATDK se refiere a la Danza como comunicación y relación con el mundo exterior. Si partimos de que todo arte es un modo de expresión, un vehículo para comunicarse con el medio, por supuesto 
la Danza forma parte de esta categoría. Vamos a enumerar varios filósofos y pensadores que coinciden con ATDK al definir cualquier acto creativo.

J. Pallasmaa aludiendo a la creación llama la atención hacia estos dos elementos y el diálogo entre ellos: "Durante su aparición, el trabajo creativo exige dos focos simultáneos: el mundo y el yo. Como consecuencia de este doble foco, toda obra significante en esencia constituye una representación microscópica del mundo y, al mismo tiempo, un autorretrato inconsciente" $(2012,140)$.

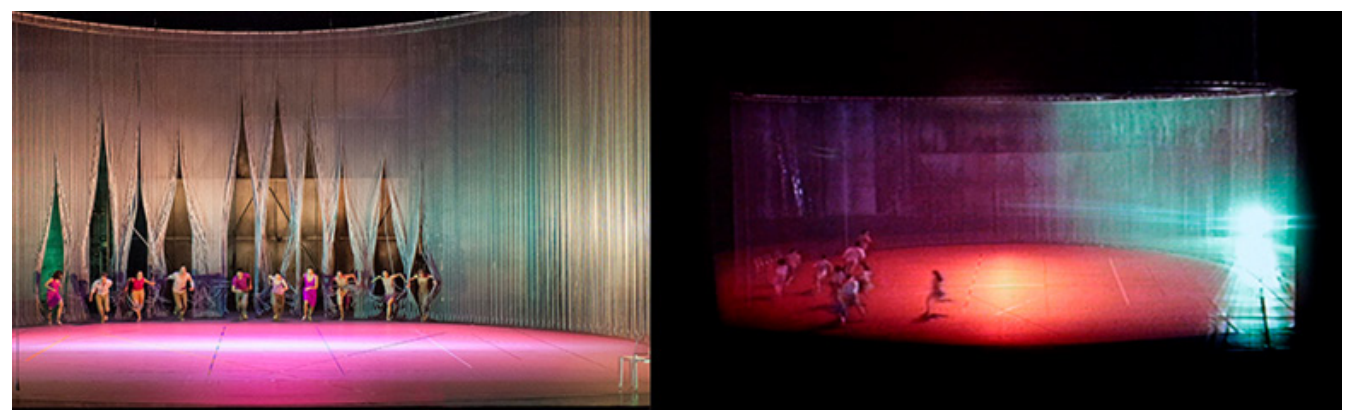

Fig. 7 Rain 2001

Efectivamente existe un mensaje detrás de cada pieza, si bien Fase podría considerarse minimalista, abstracto, donde el virtuosismo compositivo y técnico predominan, constituye un manifiesto de la danza contemporánea, en él encontramos muchos detalles irónicos hacia la danza clásica, como pueden ser los movimientos de los pies subiendo a puntas con la zapatillas deportivas, el simple hecho de andar, o la naturalidad y complicidad de miradas entre bailarinas.

A través de la danza reivindica y expone asuntos del momento, Rosas danst Rosas nos muestra la feminidad desglosada en todas sus dimensiones, la fuerza, la sensualidad, el erotismo, la defiende.

Relaciones entre cuatro mujeres a través de gestos cotidianos y muy femeninos, los cuales mediante la repetición y la abstracción nos llevan a narrativas emocionales.

Continuando, en el campo de la Literatura, cita Rushdie (1991, 417): "La literatura está hecha entre el yo y el mundo, y es durante el acto creativo cuando 
esta línea limítrofe se difumina, se torna permeable y permite que el mundo fluya en el artista y que el artista fluya en el mundo".

En las creaciones de ATDK encontramos estos paralelismos, se trata de contar historias, sentimientos, ideas, de lo cercano, de lo que nos pasa, en conexión con el medio que nos rodea, con los pies posados en el suelo y los poros de la piel atentos a lo que sucede a nuestro alrededor. La fuente de inspiración está en la propia realidad, hay que saber interpretarla para trasmitirla. Por ejemplo en Elena's Aria (1984), se plasma la impotencia hacia el paso del tiempo, hacia una ausencia irremediable, una atmósfera de frustración y cansancio.

Volviendo al recorrido de esta idea en otras artes, Pallasmaa corrobora al hablar sobre la creación en Arquitectura: "Seguramente la Arquitectura se concibe y experimenta en esta línea limítrofe y existencial y no existe ninguna experiencia artística o arquitectónica sin que exista la fusión del espacio y del sentido del yo/ del observador/oyente/ habitante" (2012, 140).

Por último, citando otra de las artes, Merleau Ponty reitera el planteamiento: "Qué otra cosa podría expresar el pintor o el poeta más que su encuentro con el mundo"3.

En tercer lugar la "Danza como elemento trasmisor entre el cielo y la Tierra", canalización de un cierto misticismo o como metáfora de un articulación entre lo concreto y lo abstracto. En sus propias palabras: "Bailar es llevar el mundo consigo mismo, en su cuerpo, de forma muy concreta y actual: un cuerpo de hoy no se mueve como un cuerpo de hace cien años...los movimientos revelan los modos de vida. Al fin y al cabo todo es energía materializada y nosotros somos eso, energía convertida en materia" (Guisgand 2008, 12).

Por tanto el movimiento surge de un impulso, de una energía y se trasforma de diversas maneras, y en este sentido podría entenderse el cuerpo como una reducción del mundo, del macrocosmos que le rodea; las dos espirales entrelazadas del ADN, se ven reflejadas en múltiples movimientos del cuerpo humano, en algo tan sencillo como es andar por ejemplo. Todas esta energías se traducen en movimientos concretos como girar, andar, saltar, mover los brazos (de múltiples formas), movimientos cotidianos y naturales, como retirarse el pelo de la cara, balanceos de brazos, espirales, desequilibrios, combinados con un lenguaje a veces clásico, se trata de un movimiento a partir de la noción de cuerpo democrático para permitir que la energía circule más libremente. 
En último lugar "Danza como expresión de sentimientos que el cuerpo lleva consigo"; ante una danza tan matemática, abstracta y calculada parece complicado creer que se trasmitan sentimientos, sin embargo en palabras de la creadora: "No soy la "Freak de los sistemas" por la que todos me toman. La estructura me interesa, en la medida que expresa emociones"4.

Empatía y comunicación entre los otros bailarines se lee en las piezas a través de miradas, cabezas que asienten, escucha corporal integrando lo que sucede en cada momento. En su largo recorrido encontramos piezas más pasionales como "Mozart/Concert Arias"(1992) o "Amor constante más allá de la muerte" (1994) y otras que pueden parecer más distantes, herméticas quizá intelectuales, pero siempre palpitan sentimientos bajo esta apariencia. Bien es cierto que se trata de otro tipo de lenguaje y de trabajo muy distinto al que pueden ofrecer coreógrafos como Wim Vandekeybus, cuya obra está cargada de emociones fuertes y gran visceralidad, o Pina Bausch que nos confronta con nosotros mismos y su obra constituye un legado de emociones.

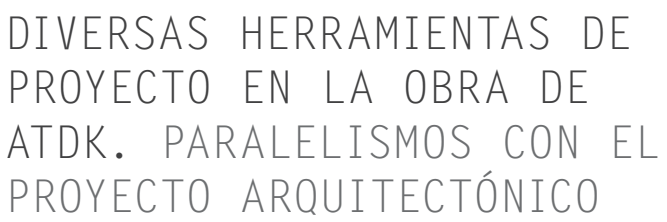

Una vez dibujado este esbozo de ATDK, queda delimitada la silueta de su obra y su concepto de la Danza desde determinada perspectiva. La creadora se sitúa en un plano dialógico ${ }^{5}$ de interacción entre disciplinas, con la mirada siempre en la Música, la Geometría, la Arquitectura, la Literatura, el Teatro, estableciendo diálogos cruzados. Es capaz de aglutinarlo con lo que podríamos llamar su "arquitectónica" 6 o sistema que organiza las relaciones entre las partes. Como hemos visto siempre existe una macroestructura que engloba y alberga todas las fracciones, ya sea basada en la música, en el espacio o en ambas. Al igual que en Arquitectura existe un orden mayor que ordena y da unidad al conjunto, en palabras A. Campo Baeza (2010): “(...) aquellas estructuras no solo transmiten las cargas sino que además, lo más importante, establecen el orden del espacio. Y este orden del espacio está desde el primer momento en la génesis de cualquier proyecto. Como el esqueleto del ser humano". 
Igualmente este orden espacio-temporal está presente en todos los proyectos de la coreógrafa. Posteriormente aparecerá una subestructura de segundo orden, otra de tercero y así sucesivamente hasta llegar a la mínima unidad, molécula y germen del proyecto, que ella llama la "frase de base". Esta "frase base", célula generatriz, lo que sería el módulo en Arquitectura, en ocasiones es ínfima, en otras ocasiones es una unidad de cierta entidad, y se va construyendo progresivamente, va mutando, se va declinando, va sufriendo transformaciones a través de diferentes recursos y parámetros espacio-temporales para dar lugar a los complejísimos sistemas que constituyen sus piezas. Siempre a partir de la máxima simplicidad, como reflejo del principio de Mies "Menos es más", en sus propias palabras": "Lo que pretendía era, ser lo más económica posible, de un mínimo sacar lo máximo".

Llegar a una elevada e interesante complejidad a través de elementos básicos y sencillos, a través de distintas herramientas de proyecto, es lo que se propone ATDK. Recursos muy utilizados por el Minimalismo y de gran efectividad, utensilios clave, que nos permiten construir, en Arquitectura, en Danza o en Música. A continuación pasamos a estudiar dichos mecanismos empleados en su producción y presentes en toda su obra. Leyes compositivas que manipulando variables van generando el elaborado conjunto. Tales son el dibujo, la estructura-módulo, ritmo-operaciones temporales, la repetición-acumulación-superposición de capas.

\section{DIBUJ0}

El dibujo como si de un volumen cristalográfico se tratara, nos presenta múltiples facetas como mecanismo de trabajo, todas ellas nos aportan en el campo de la creación e interpretación, ya se trate de Arquitectura o de Danza.

"La imagen mental inicial puede surgir como una entidad visual, pero también puede ser una impresión táctil, muscular o corporal, o una sensación informe que la mano especifica en una serie de líneas que proyectan una forma o una estructura. Uno no puede saber si la imagen surgió antes en la mente y fue entonces cuando quedó registrada por la mano, o si la mano produjo la imagen de una manera independiente, o si surgió como resultado de una colaboración fluida entre la mano y el espacio mental del dibujante. A menudo es el propio acto de dibujar, el profundo compromiso en el acto del pensamiento incons- 
ciente a través de la creación, lo que da origen a una imagen o una idea. En inglés la palabra "dibujar" (drawing) tiene un segundo significado- extraer- y señala este significado esencial del dibujo como un medio de extraer, de hacer patentes y concretas unas imágenes mentales internas y unos sentimientos tanto como registrar un mundo exterior. La mano siente el estímulo invisible y amorfo, lo coloca en el mundo del espacio y de la materia y le da una forma" (Pallasmaa 2012, 101-2).

Pallasmaa reflexiona sobre el sentido del dibujo y el acto de dibujar, que sin saber bien su procedencia, si es física o mental, ayuda a materializar ideas, sentimientos, imágenes. Efectivamente se trata de una útil herramienta no sólo para los arquitectos sino también creadores de otros ámbitos, ya sea la Pintura, la Escultura, la Danza... Alvar Aalto reafirma el potencial del hecho de volcar gráficamente estas ideas: "Sólo la ejecución de las ideas hace que éstas sean más reales. La idea no se hace verdaderamente real hasta que no se plasma sobre el papel; este es el ineludible segundo paso en el camino hacia la arquitectura construida" (Aalto 2010).

Así el dibujo puede entenderse como la poiesis, como la define Platón en el Banquete, la causa que convierte cualquier cosa que consideremos no ser a ser; en este sentido hablaríamos de una energía de impulsión creadora, que de manera más o menos consciente plasma conceptos. Una explosión que hace brotar, desarrolla pensamientos, activa ideas.

Esta fuerza generadora, no es una dinamo sin más, si no que contribuye a engranar niveles de pensamiento, interconectar dimensiones. "Mientras proyectaba la biblioteca municipal de Viipuri, pasé largos períodos buscando soluciones al azar mediante dibujos ingenuos (...) Mis dibujos infantiles sólo tenían relación indirecta con el pensamiento arquitectónico, pero me condujeron en todo caso a la interconexión de la sección con la planta y a la unión armónica entre construcciones horizontales y verticales" (Aalto 1948).

Es evidente que grafiar, además de ser una potencia motriz de creación que comunica el mundo de las ideas con el mundo real, también ofrece esa posibilidad de expresar complejidades espaciales que no son fáciles de exteriorizar de otras formas, como puede ser pasar de la bidimensionalidad a la tridimensionalidad, implicar más relaciones de las que meramente vemos en un plano. Por tanto otra faceta más de los trazos es la de utensilio de compresión para propios y ajenos, es decir tanto para el autor como para el espectador o para el intérprete, el apunte sirve de explicación, de guía, cada uno al nivel que la 
necesite. Como si de una partitura se tratase, y a modo de hoja de ruta, el "plano" nos va explicando y guiando por el acontecimiento arquitectónico, dancístico o musical. Surge así el concepto de notación, el dibujo como notación, como alfabeto de signos gráficos que recoge y estampa conceptos, ideas, historias, edifcios...En el contexto musical y arquitectónico, la notación ha sido algo muy natural y aceptado universalmente desde antigüio, sin embargo en el terreno de la danza, quizá por la complejidad que ésta supone (porque sería aunar espacio, tiempo y movimiento) existen múltiples tentativas y sistemas de notación, pero no se ha llegado a una unificación universal. Ya desde el S. XV-XVI se comienza sistematizar con sistemas varios y a pesar de las múltiples investigaciones y sistemas de notación a lo largo del tiempo como la Labanotación, la notación Movimiento Benesh, Eshkol-Wachman Movimiento Notación, el Dance Writing por citar algunos, no ha habido convenio ni aceptación universal. El individualismo en este aspecto es notable, cada coreógrafo o bailarín inventa o idea el suyo propio, a modo de boceto y registro.

La dificultad de registrar gráficamente esta complejidad de datos, también se la plantea y la pone en cuestión la Arquitectura, ya que en cierto modo le atañe. Podemos ver reflejada esta inquietud en el texto de B. Tschumi ${ }^{8}$ : "La finalidad del modo de notación tripartito (acontecimientos, movimientos, espacios) es la de introducir el orden de la experiencia, el orden del tiempo-los momentos, los intervalos, las secuencias-porque todas intervienen

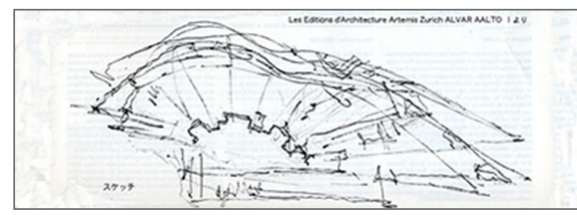

Fig. 8 Alvar Aalto Croquis para Viviendas en Bremen 1958-1962.

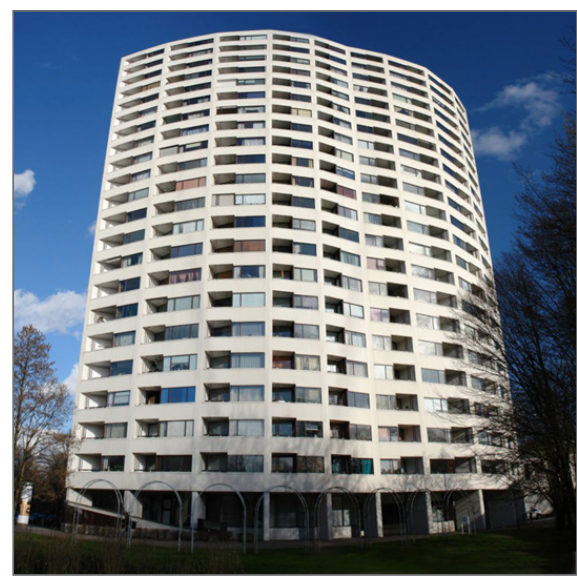

Fig. 9 Alvar Aalto, Viviendas en Bremen 1958 1962.

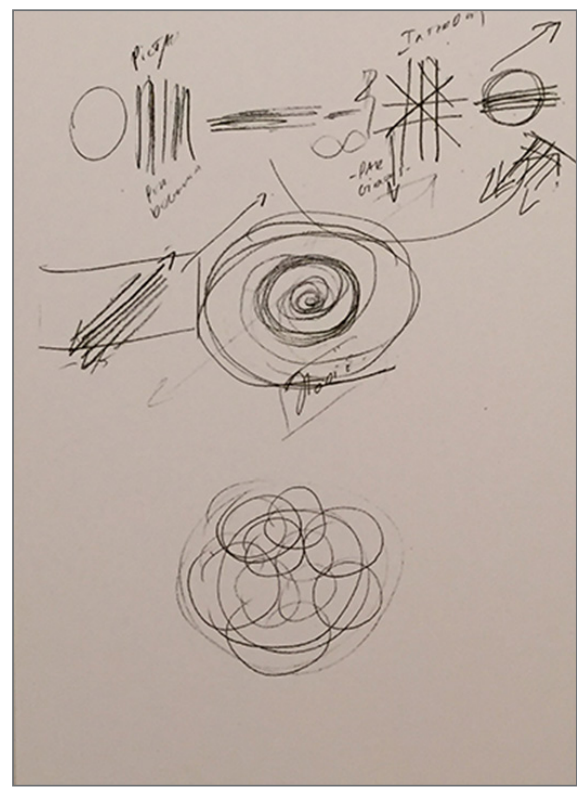

Fig. 10 A.T. de Keersmaeker, croquis para Cesena 2011. 
en la lectura de la ciudad. Esta notación proviene igualmente de la necesidad de cuestionarse sobre los modos de representación utilizados por los arquitectos: plantas, secciones, axnometrías, persepctivas. (...) Notación: procedimiento o método que consiste en representar, números, cantidades, etc., mediante un sistema de signos. Los movimientos- de gentío, de bailarines, de luchadores-recuerdan la intrusión inevitable del cuerpo en los espacios de la arquitectura, la intrusión de un orden en el interior de otro. (...) Esta notación intenta eliminar significados preconcebidos otorgados a las acciones particulares, para concentrarse sobre todo en su efecto espacial: el movimiento del cuerpo en el espacio".

Ciertamente Tschumi polemiza sobre los modos de representar la Arquitectura y plantea esa necesidad tripartita que incluye espacio-movimiento y tiempo. Como hemos comentado en Danza no existe una unidad al respecto y cada maestro encuentra su camino.

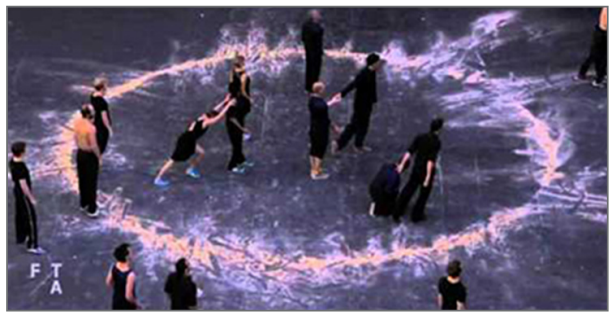

Fig. 11 A.T. de Keersmaeker Cesena 2011.

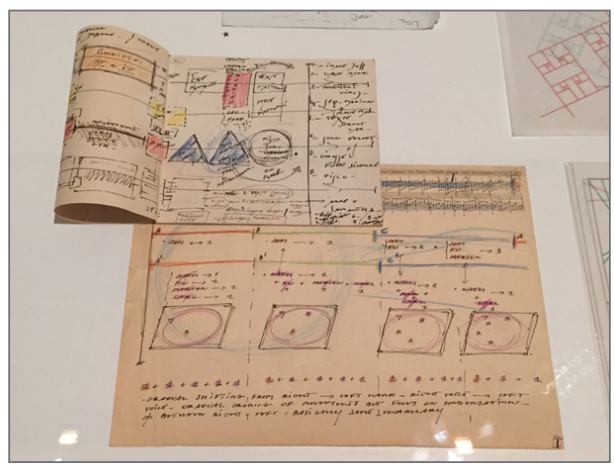

Fig. 12 A.T. de Keersmaeker Cuadernos de trabajo con croquis de varias coreografías (Erts 1992 y Achtaerland 1990)
Teniendo en cuenta todas estas caras del dibujo, a modo de cristal, analizamos la utilización del mismo por ATDK que ciertamente está patente a lo largo de todo su recorrido. Primeramente lo utiliza desde el comienzo como semilla de un proyecto, como epicentro, como fuente inspiradora, al igual que un croquis de Aalto es el germen de un edificio. A veces el "dibujo gráfico" en este estadio del proceso, se retroalimenta con el dibujo espacial y corporal, trazos tridimensionales bailados (Figs. 8, 9, 10 y 11).

Vemos pues, que al igual que al arquitecto, los croquis previos que ATDK realiza le permiten a concretar y llevar a cabo realidades. En las imágenes se observa el ejemplo de Cesena pero esta forma de aproximarse al proyecto es una constante. ( Drumming, Rain, 
Rosas danst Rosas, Fase, Vortex Temporum, Just Before, Barba Azul, Partita2...)

En un segundo momento, el dibujo como herramienta de trabajo, para ir desarrollando, cristalizando propuestas, comprendiéndolas y trasmitiéndolas, de la misma manera que los croquis y avances de proyecto le sirven al arquitecto en el curso del proceso (Figs.12 y 13).

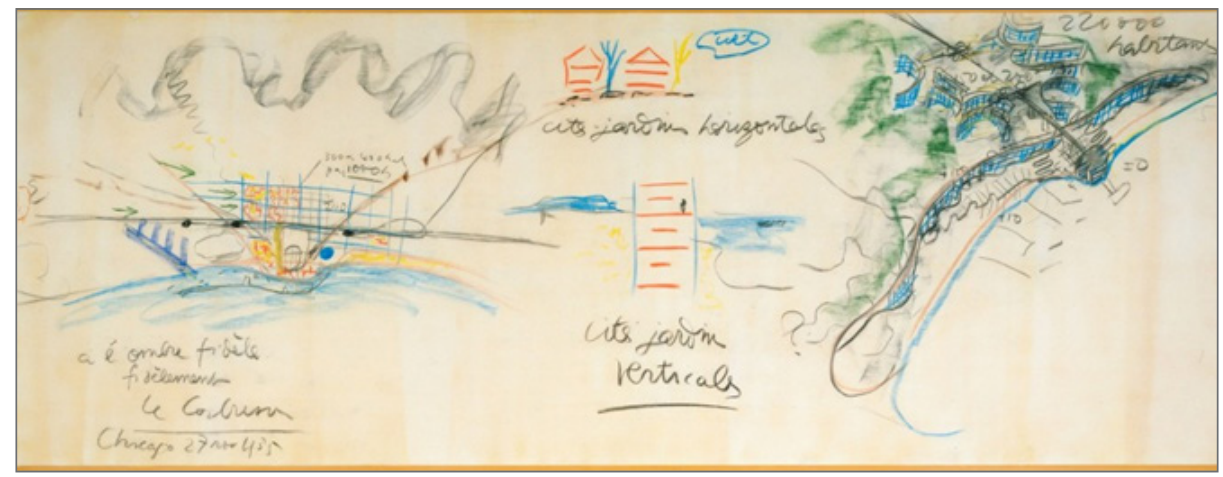

Fig. 13 L.Corbusier, Croquis de trabajo para plan urbanístico de Argel. 1935.

La bailarina y coreógrafa realiza croquis que engarzan las diferentes dimensiones para dar a conocer el material a los intérpretes y que puedan llegar a ser dibujados por los cuerpos en el espacio. Teniendo como guía el esbozo inicial se va montando coreografía y constituirá el orden espacial durante todo el proceso. Este paso queda ilustrado con el ejemplo de los sucesivos dibujos que sustentan Drumming. En la imagen se observa la superposición sucesiva en el tiempo de tramas diferentes. Esta etapa podría compararse con un nivel de definición más exhaustivo del edificio, planos detallados, incluyendo secciones o incluso detalles constructivos. (Figs.14 y 15).

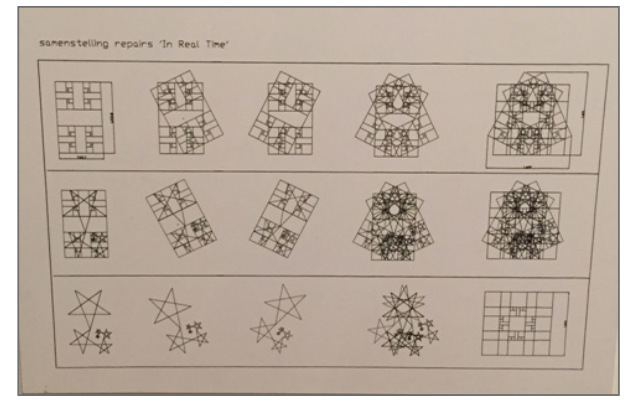

Fig. 14 A.T. deKeersmaeker, Evolución geométrica espacial y temporal de Drumming. 1998.

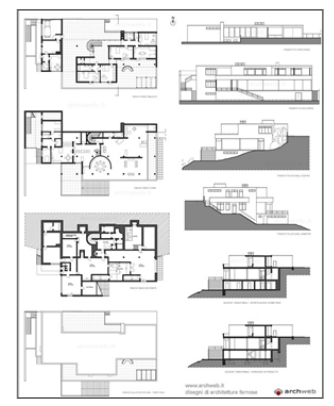

Fig. 15 M. van der ROhe, Casa Tugendhat 1930. 
En último lugar, destacar que ATDK también aplica el artilugio de trabajo que nos ocupa como notación. Como partitura en vivo, en ocasiones dibujada en la propia escena y que forma parte del espectáculo, incluso en ciertos espectáculos se dibuja en directo, como en Work/Travail/Arbeid o en Drumming. Por otro lado, es evidente que los documentos gráficos a modo de notación van a servir para registrar y poder trasmitir en un futuro su legado. El equivalente en Arquitectura a dicha notación serían los planos definitivos del edificio, constructivos que sirven para la ejecución y posteriormente para su archivo (Figs. $16,17,18,19,20)$.

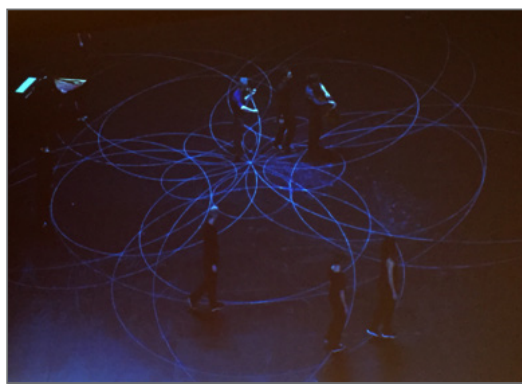

Fig.16 ATDK Vortex Temporum 2013

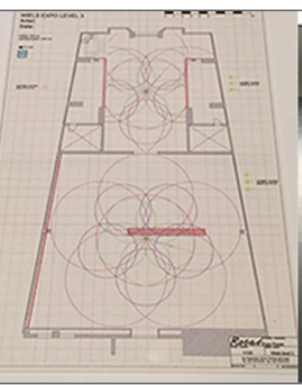

Fig.17 ATDK Planos para Work/Travail/Arbeid en Wiels 2015.

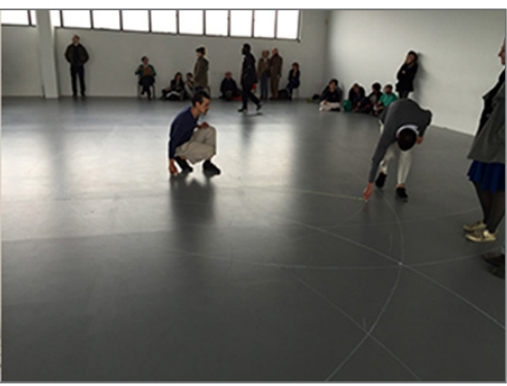

Fig.18 ATDK Work/Travail/Arbeid. Bailarín redibujando trazas. Wiels 2015

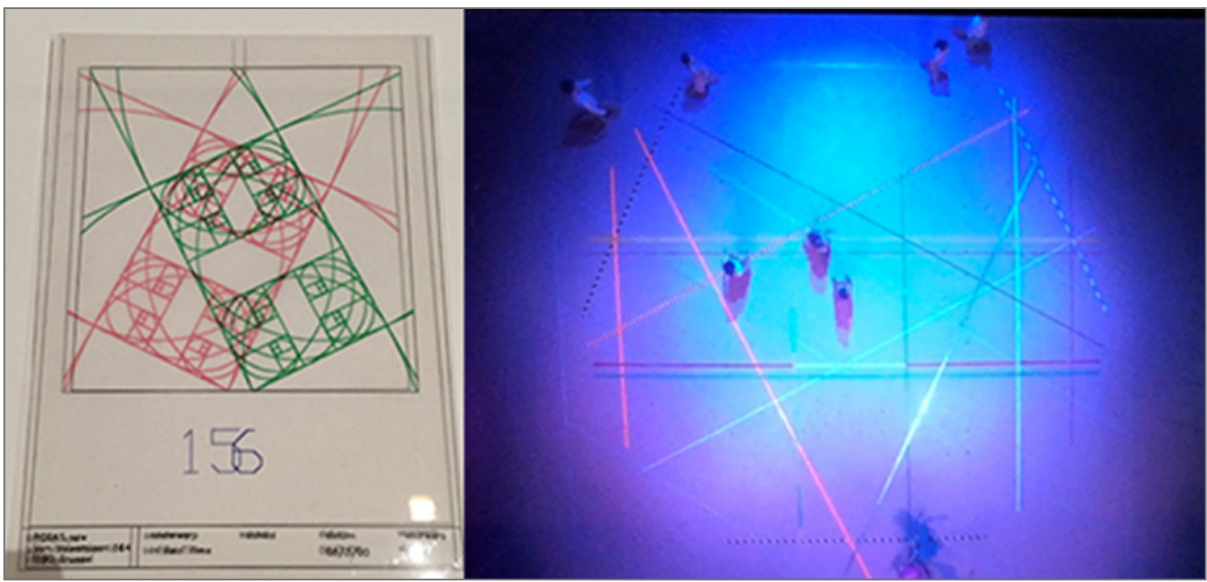

Fig.19 ATDK Planos para Drumming 1998.

Fig. 20 ATDK Drummng en escena.

En cuanto al tipo de dibujo, dado su gran interés por la geometría platónica, la sección áurea, el cuadrado mágico, la numerología, las formas puras y sencillas, éstas son las que aparecen de manera recurrente en sus composiciones (el círculo, el cuadrado, la espiral, el pentágono...). 
Para culminar haciendo referencia a estas formas geométricas tan familiares a la artista, y volver a subrayar su estrecha relación con la arquitectura traemos a colación esta evocadora cita de Toyo Ito (1992): "Proyectar arquitectura es un acto de generar vórtices en las corrientes del aire, viento, luz sonido".

Los vórtices de la Mediateca de Sendai de Toyo Ito, encuentran su paralelismo en los orígenes de las espirales, de Rain de ATDK. Son las llamadas "casas" por ATDK, que tiene cada uno de los bailarines de la pieza, y es de donde nace el movimiento; en la mediateca estos polos realizan también su función, pero además generan movimientos y recorridos en los usuarios que pueden reflejarse en las espirales de la pieza (figs. 21 y 22).

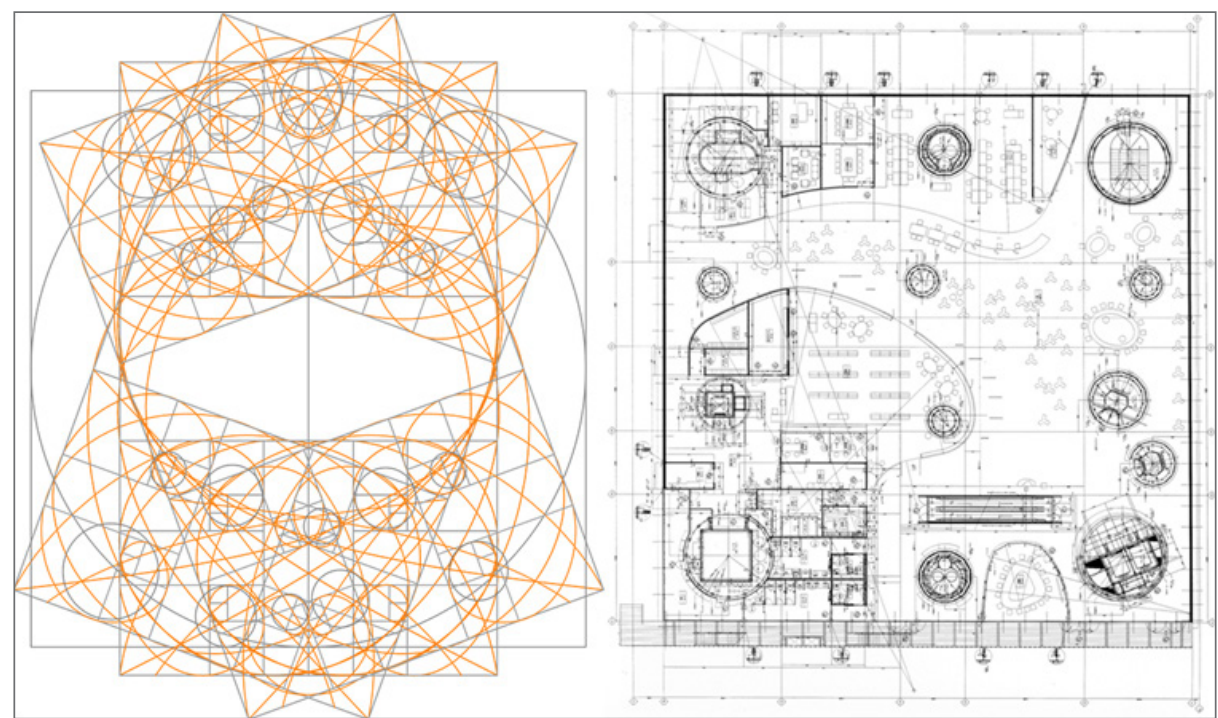

Fig. 21 ATDK Rain 2001.

Fig. 22 Toyo Ito, Mediateca de Sendai 2006.

\section{ESTRUCTURA}

"Cuando digo que la gravedad construye el espacio, estoy hablando de la estructura, de la llamada estructura portante. De la estructura que a lo largo de la Historia ha generado la forma arquitectónica. Casi siempre la forma de la arquitectura ha ido, lógicamente, ligada a la estructura portante. Es más estructura y forma y espacio han sido siempre la misma cosa. (...) La estructura no sólo soporta y trasmite las cargas, sino que establece el orden del 
espacio, construye el espacio... resuena y suena como un instrumento musical cuando acordado por el aire" (Campo 2010).

Esta reflexión de A. Campo Baeza sobre la función de la estructura como elemento definidor del espacio, está en total concordancia con la noción de estructura que utiliza y aplica ATDK. Como hemos expuesto anteriormente la estructura organiza espacialmente sus obras, y más aún cuando esta macroestructura es una base gráfica generadora. ¿Y qué es lo que compone esta estructura? Como en Arquitectura, donde la estructura define el módulo, o bien el módulo configura la estructura, en la Danza de ATDK un sencillo módulo da lugar al complejo entramado de la estructura, es la llamada por ella frase de base. Atendiendo a la definición de módulo: "Se conoce como módulo (del latín modulus) a una estructura o bloque de piezas que, en una construcción, se ubican en cantidad a fin de hacerla más sencilla, regular y económica. Todo módulo, por lo tanto, forma parte de un sistema y suele estar conectado de alguna manera con el resto de los componentes" 9 .

Efectivamente esta primera unidad o enunciado dancístico puede asimilarse a muchos de los entes unitarios arquitectónicos que aparecen desde antiguo en la Arquitectura. Sus características son las mimas, forma parte de una construcción, haciéndola más sencilla, uniforme, simple y al mismo tiempo está articulada y relacionada con el todo, por distintas leyes. Dentro de la Arquitectura un ejemplo muy gráfico serían las celdas habitacionales que L.Corbusier proyecta en La Unité d'habitation en 1947, pero habría infinitos. Existe además una peculiaridad en los módulos que construye esta autora, y es que su propuesta unitaria no se mantiene constante en el tiempo, sino que evoluciona, crece, se expande, se declina, se trasforma, muta, se adapta al "terreno". Una manera de proyectar como podría ser la de A.Aalto, A. Jacobsen o J.A. Corderch en por nombrar algún ejemplo. De esta forma el módulo de ATDK irá en cada caso dibujando la malla que sustenta la pieza. Es por tanto esta matriz de movimiento, la que genera el conjunto. Por ejemplo en el caso de Fase, en Violin Fase los principios de movimiento son la rotación, la espiral, el balanceo de brazos, la marcha, el balanceo de piernas y el salto. Los movimientos se sitúan en la parte superior del cuerpo sobre todo, dando una verticalidad al conjunto y rara vez se cambia el eje. Los movimientos pivotan sobre el eje de la columna vertebral y parten de los brazos, si bien se mantiene este eje, la direcciones cambian constantemente. Existen pues tres "módulos base" de movimiento muy sencillos $A, B$ y $C$ que se van combinando y tejiendo; esta sintaxis evoluciona a través de herramientas que veremos posteriormente como la repetición, la acumulación y el cambio de ritmo, desfase... Aparece el 
círculo, dos direcciones dentro de él, y después una serie de 11 variaciones de círculos, combinando las distintas direcciones y espacialidades posibles. Pero toda esta primera parte está generada por los tres módulos unitarios. Igualmente el segundo movimiento Come Out, en su conjunto consta de tres movimientos $2 / 6,2 / 4$ y 5 que se repiten tres veces con diferentes combinaciones de direcciones espaciales. Las frases de base son dos A y $B, B$ contiene a su vez a A. Cada intérprete baila combinaciones diferentes de estas frases y van teniendo lugar cambios de direcciones y desplazamientos espaciales al mismo tiempo. Teniendo la base el círculo de nuevo y la espiral, en esta ocasión en el nivel medio (las bailarinas están sentadas) la coreografía va discurriendo transitando por los nueve momentos; las bailarinas se encuentran a la izquierda del proscenio y la iluminación tiene diferente dirección según el bloque de la pieza (fig. 23).

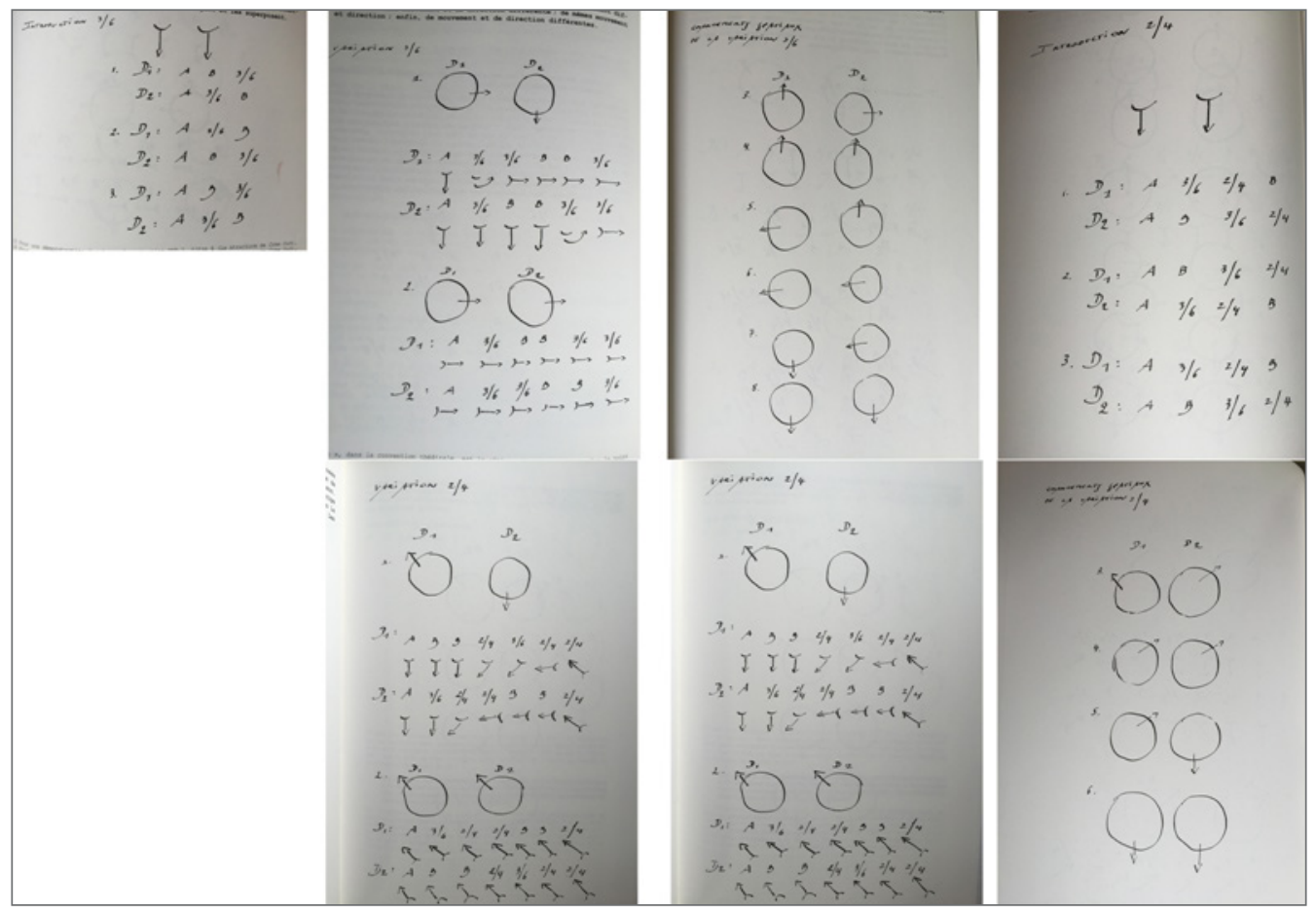

Fig. 23 ATDK, Notación-Esquama de los bloques y frase base de Come Out, Fase, 1982.

La tercera parte, Piano Fase, presenta una estructura tripartita y se desarrolla de la mano de la música y sus herramientas (el desfase sobre todo y siguiendo tres versiones de un modelo rítmico tocado por dos pianos).Se trata de una compleja configuración pero que gracias a los módulos base es posible de 
realizar. Podría resumirse que son variaciones sobre el andar, andar girando, andar sobre una pierna guiados por un brazo y el torso. Como en Violin Fase los brazos dirigen, tanto la marcha como la rotación. El conjunto se sitúa en una línea paralela al proscenio. Presenta tres frases base muy similares $A, B$ y $\mathrm{C}$ que se agrupan a su vez en una secuencia de base:

$\mathrm{ABC}_{4}$

$\mathrm{A} \mathrm{C}_{4} \mathrm{~B}$

$\mathrm{A} \mathrm{C}_{4} \mathrm{C}_{6} \mathrm{~B} \mathrm{C}_{6}$

$\mathrm{A} \mathrm{C}_{6} \mathrm{~B} \mathrm{C}_{4} \mathrm{C}_{6}$

La secuencia se realiza al unísono y va variando sus calidades (fluida, en suspensión y atacada). La pieza consta de tres bloques (modelos a 12 tiempos, modelos a 8 tiempos y modelo a 4 tiempos) conformados por variaciones de esta secuencia base.

En último lugar Clapping Music, igualmente que las otras tres partes, está construida sobre el desfase, pero en este caso no por aceleración sino por deceleración. Los intérpretes siguen el mismo patrón, van perdiendo el unísono hasta volver a él. Y en este caso el módulo de base sería un salto.

Podríamos continuar analizando de la misma manera muchas otras piezas, pero dentro del marco de este artículo sería demasiado extenso y consideramos que queda suficientemente claro, cómo utiliza ATDK la estructura y el módulo como herramientas de proyecto en la Danza, a semejanza de la Arquitectura. Cómo efectúa la transición de una escala macroscópica a una microscópica.

\section{REPETICIÓN}

"Repetir es comportarse de una manera determinada, pero en relación a algo único, singular o equivalente.(...) La repetición no cambia nada en el objeto repetido, solo en la mente que lo contempla." (Deleuze 1994, 70). Esta observación de Deleuze sobre el concepto repetición y sus efectos, pone de manifiesto la potencia de esta estrategia de creación. La repetición conduce a un 
estado mental especial, de concentración, de abstracción. Efectivamente ha sido utilizada en todos los campos creativos a lo largo del tiempo. En la Arquitectura, empleada de muy diferentes maneras, desde el diseño de ciudad romana siguiendo un esquema de retícula de "insulae" que se repiten y conforman el "cardus" y el "decumanus", hasta los esquemas urbanísticos propuestos por la arquitectura moderna. A este respecto María Teresa Muñoz y Juan Antonio Cortés $(1981,230)$ explican: “... los arquitectos modernos traen, de la mano de su voluntad de purificación e higiene, una ciudad constituida por unidades de edificación aisladas y elementales que se repiten hasta el infinito".
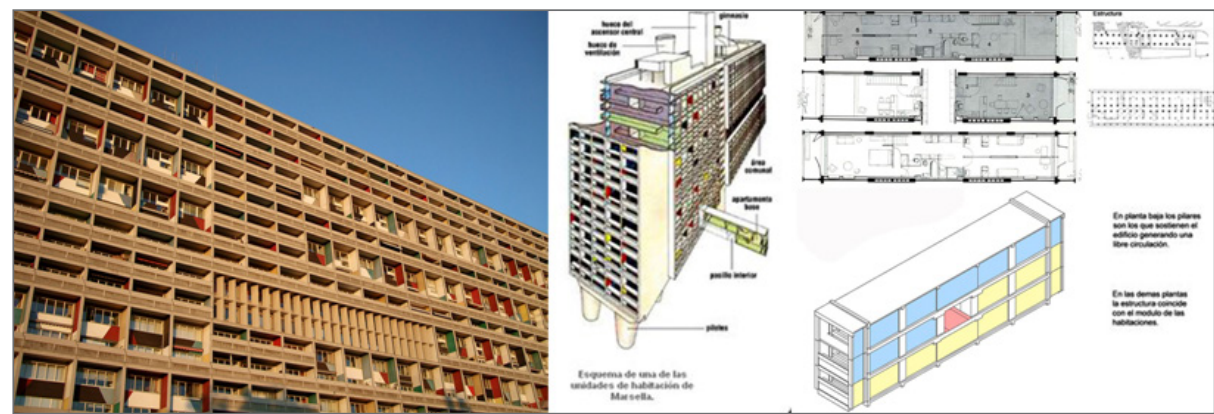

Fig. 24 L.Corbusier. L'Unité d’Habitation, el módulo-célula de habitación y la estructura general.

Asimismo, las células habitacionales de las que hablábamos anteriormente, repetidas y variadas con diferentes parámetros, tan empleadas por arquitectos del movimiento moderno. (Fig.26)

De manera especial contemplamos esta táctica en los años 60-70 con la aparición del Minimalismo. Tanto en Arte, como en Música, en Literatura y por supuesto en Danza. El historiador de arte C. Owens al disertar sobre la repetición en el minimalismo y en el arte conceptual dice: “... estas repeticiones eliminan cualquier referencia fuera de las series en sí mismas, al igual que cualquier relación subjetiva entre el artista y el espectador...cada una ausente para la otra" (Owens 1981)

Correspondiendo a su tiempo ATDK emplea esta estrategia para coreografiar. Si bien es cierto que le preceden varios creadores, por un lado americanos, sobre todo los pertenecientes al Chudson Dance Theatre (T. Braun, L. Childs) por otro en Europa P. Bausch, ella desarrolla su propia identidad. Por otro lado siempre ha estado muy influenciada y ha admirado al músico minimalista $\mathrm{S}$. Reich, trabajando con y sobre su música, por tanto no es de extrañar el uso de la repetición como artefacto. Estudiemos un ejemplo del empleo de ATDK de 
la repetición: Rosas danst Rosas. Esta pieza para cuatro bailarinas y divida en cinco secciones explora los tres niveles:

- nivel bajo-suelo-estar tumbado

- nivel medio-estar sentado

- nivel alto-estar de pie-caminar

El material pertenece a movimientos cotidianos femeninos, de autoafirmación y seguridad pero sin ninguna carga emocional. Movimientos rigurosos y precisos organizados en secuencias que las intérpretes van ejecutando de manera repetitiva, como si de un engranaje maquinal se tratase.

Las repeticiones se permutan mientras viajan por el espacio, obedeciendo a una malla espacial invisible que encarnan las bailarinas. El cuarteto va dibujando líneas y direcciones en el espacio muy claras, geometría pura bailada (fig. 25).

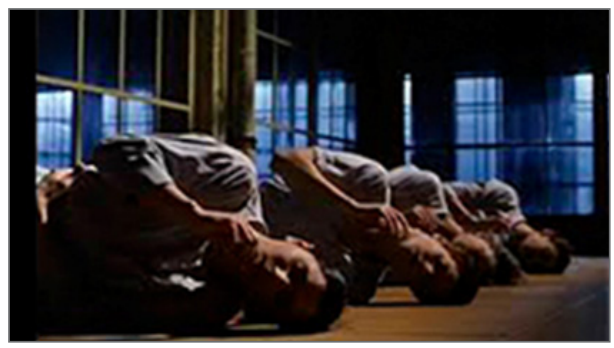

Fig. 25. ATDK, Momento de Rosas danst Rosas, 1983.

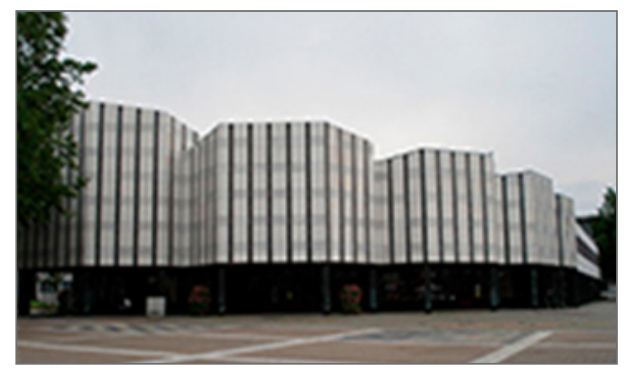

Fig. 26 . A. Aalto, Centro Cultural en Wolfsburg 1958.

La energía a lo largo de la repetición de estos patrones va variando, ATDK introduce sutiles variaciones según trascurre. Vista en su conjunto, la pieza como una estructura reticular a modo de juego de ordenador focalizado en las repeticiones; lo cual corresponde bastante con la idea que describe Owens. Todas estas repeticiones en serie consiguen un efecto, como decía Deleuze y al igual que lo consigue con la repetición- variada en Arquitectura. Se crean niveles de significado que superan el contenido del propio material repetido. Aparecen tensiones sin resolver, y la abstracción lleva a convertir comportamientos sociales triviales (gestos adolescentes) en rituales obsesivos con nuevo significado. Rosas danst Rosas Podría decirse que está a medio camino entre dramaturgia y abstracción formal. Reaparece la idea de circularidad, no solamente a nivel formal y gráfico, sino como un bucle interminable, terminar para volver a empezar. 
Añadir al ya mencionado mecanismo, otros como son la acumulación, la variación y la superposición de capas. Estos sirven a ATDK como estrategias coreográficas e igualmente se utilizan con frecuencia en el terreno de la Arquitectura.

Como cierre de este epígrafe y a modo de recapitulación cito directamente a la autora: "Por debajo del concepto y de la composición coreográfica de este espectáculo está la exploración de dos conceptos aparentemente opuestos: el trabajo con patrones matemáticos y repetitivos suele excluir la profundidad emocional. A través de la utilización de elementos puramente coreográficos (la elección de los movimientos, la ordenación espacial, el ritmo, las conexiones entre danza y música, la calidad y energía del movimiento, la estructura de las frases) esta pieza intenta crear una intensidad dramatúrgica considerable. Estos elementos que no pueden separarse, están absorbidos por una estructura rigurosa. Es justamente esta rigurosidad la que pone de manifiesto el valor de las unidades. De esta manera algunos movimientos y posturas tomados de la vida cotidiana, más que del lenguaje de danza tradicional, adquieren una importancia coreográfica".

\section{RITMO}

En último lugar, concluimos con el ritmo, como herramienta creativa. "Ritmo:

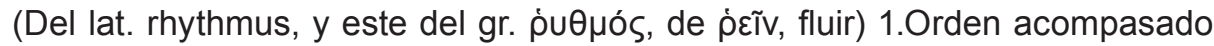
en la sucesión o acaecimiento de las cosas.2. Grata y armoniosa combinación y sucesión de voces y cláusulas y de pausas y cortes en el lenguaje poético y prosaico. 3. Metro o verso. Mudar de ritmo. 4. Mús. Proporción guardada entre el tiempo de un movimiento y el de otro diferente"10. Esta última herramienta coreográfica atiende a un parámetro más: el tiempo. Surgen leyes de formación y patrones que en la mayoría de los casos están importados de la música pero que son de gran utilidad tanto en Danza como en Arquitectura.

ATDK hace uso frecuente del unísono y todas sus desconfiguraciones, pasando por un amplio abanico de desfases tanto por aceleración como por deceleración. Se pasa de la unidad a la desincronización para volver a la sincronía, atravesando distintos estados de desfase. El canon y el contrapunto son otros modelos de aplicar la variable temporal también muy presentes en la obra de la coreógrafa. En la lectura arquitectónica, el parámetro tiempo se sustituye 
por el espacio y los desfases, hacen referencia a distancias y proporciones. Podemos ver cómo, al igual que ATDK organiza a sus bailarines en canon, al unísono, desfasados, en contrapunto etc. la arquitectura, desplaza módulos, modifica sus proporciones, los gira, inclina, los coloca en oposición (fig. 29). Ambas disciplinas necesitan armonía para percibir belleza(figs. 27 y 28).

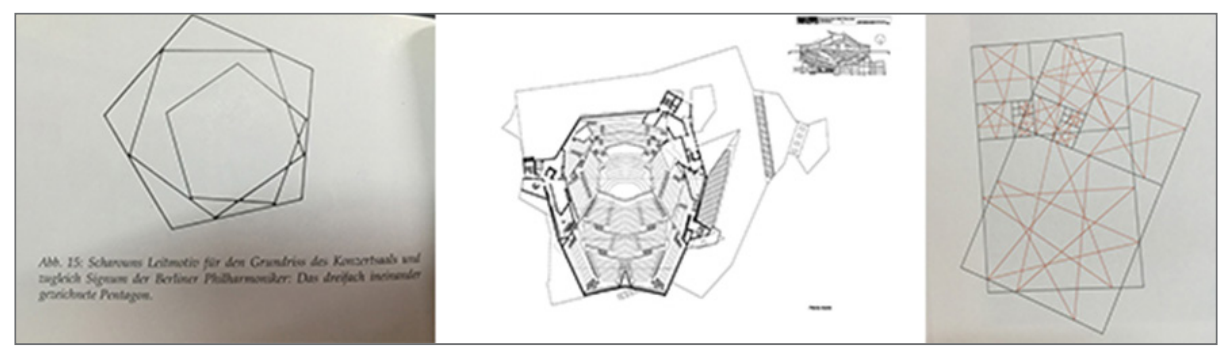

Fig. 27. H. Scharoun, Estudios Geométricos y planta de La Filarmonía de Berlin.

Fig. 28. ATDK El número de oro, basado en el pentágono, la estrella de 5 puntas, Drumming.

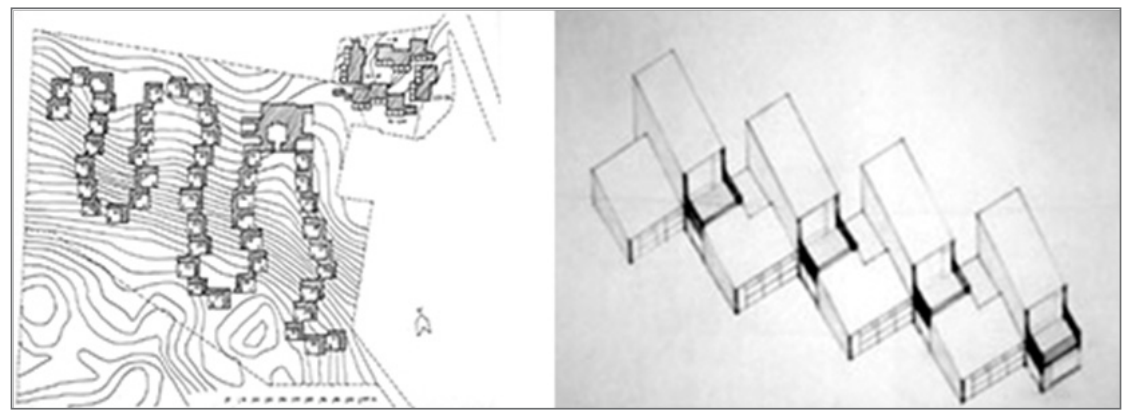

Fig. 29. Diferentes maneras de ritmar en Arquitectura.Viviendas Utzon y Jacobsen.

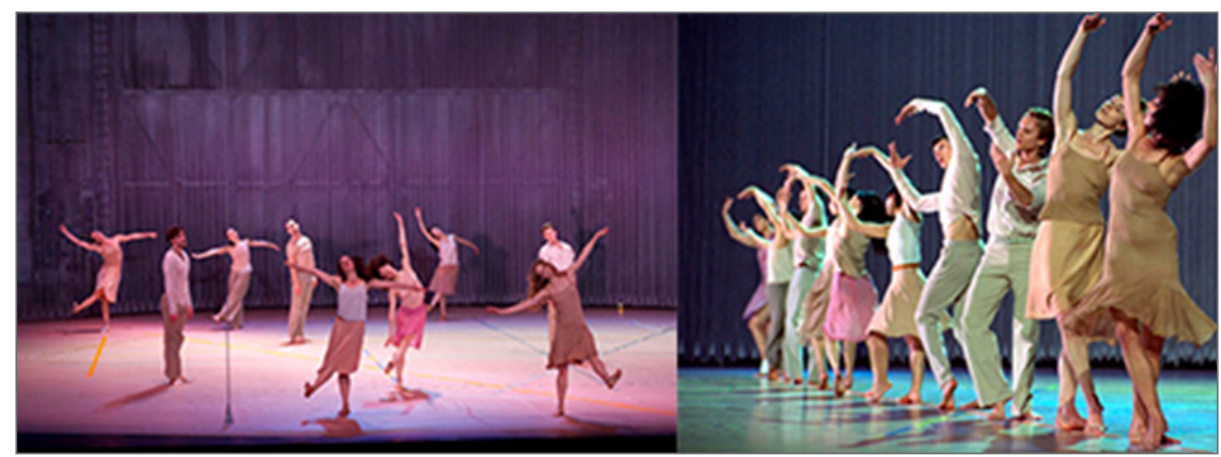

Fig. 30. ATDK, Rain, Diferentes momento de una frase de movimiento aplicando el desfase. 


\section{Referencias}

Aalto, Alvar. 1948. "Taimen ja tunturipuro" Arkkitehti 7-10

- 2010. Conversaciones con Alvar Aalto. Juhani Pallasmaa, ed. Barcelona: Gustavo Gili

Adolphe, Jean-Marc et al. 2002. "Rosas: Anne Teresa de Keersmaeker". Bruselles: La Renaissance du Libre

Bakjin, Mikhail Mikhailovich. 1981. The dialogic imagination: Four essays by M.M. Bakhtin. Austin: University of Texas

- 1989. "Las formas del tiempo y del cronotopo en la novela: Ensayos sobre poética histórica”. Pp. 207-409 en Teoría y estética de la novela: Trabajos de investigación, trad. de Helena S. Kriúkova y Vicente Cazcarra. Madrid, Taurus

Bauer, Bojana, Bojana Cvejic \& Rudi Laermans. 2011. Hear my Voice: Three essays on Keeping Still, The Song and 3Abschied by Anne Teresa De Keersmaeker, Ann Veronica Janssens, Michel François and Jérôme Bel. Brussel: Rosas

Campo Baeza, Alberto. 2010. Pensar con las manos. Buenos Aires: Nobuko

Corin, Florence et al. 2000. "Danse et Architecture”. Número especial. Nouvelles de Danse 42/43. Bruxelles: Contradanse

Cvejić, Bojana, ed. 2015. Anne Teresa de Keersmaeker: Work/Travail/Arbeid. Brussels: Mercatorfonds

Cvejić, Bojana, Plouvier Jean-Luc \& Gérard Grisey. 2013. Vortex Temporum. Brussel: Rosas

De Jong, Klaas J. et al. 2012. Music, Space and Architecture. Amsterdam: Architectura \& Natura

De Keersmaeker, Anne Teresa \& Bojana Cvejić. 2012. Carnets d'une chorégraphe: Fase, Rosas danst Rosas, Elena's Aria, Bartók. Bruxelles: Fonds Mercator

- 2013. En Atendant \& Cesena: A choreographer's score. Bruxelles: Fonds Mercator

- 2014. Drumming \& Rain: A choreographer's score. Bruxelles: Fonds Mercator

De Keersmaeker, Anne Teresa \& Guy Gypens. 2007. Fase, Four movements to the music of Steve Reich: 1982-2007. Vorst, Belgium: Rosas

Deleuze, Gilles. 1984. Francis Bacon: Lógica de la sensación. Traducción de Isidro Herrera. Madrid: Arena Libros

- 1994. Difference and repetition. Translated by Paul Patton. New York: Columbia University

Flegi, Karl, 1996. Alvar Aalto. Barcelona: Gustavo Gili

Gros, Frédéric. 2015. A philosophy of walking. London: Verso

Guisgand, Philippe. 2007. Les fils d'un entrelacs sans fin: La danse dans l'oeuvre d'Anne Teresa De Keersmaeker. Villeneuve d'Ascq: Septentrion

Guisgand, Philippe. 2008. Anne Teresa de Keersmaeker. Palermo: L’Epos

Holquist, Michael. 1990. Dialogism: Bakhtin and his world. New York: Routledge

Ito, Toyo. 1992. "Vórtice y corriente: Sobre la arquitecturacomo fenómeno”. AD 62(9/10)

Jaraíz Pérez, José. 2013. Sanaa: Espacios límites y jerarquías. Buenos Aires: Diseño

Kant, Immanuel. (1781) 2011. Crítica de la razón pura. Tecnos: Madrid 
Kästner, Irmela \& Tina Ruisinger. 2007. Meg Stuart, Anne Teresa de Keersmaeker. München: K. Kieser

Kernay, Richard, 1994. Modern movements in European Philosophy. Manchester: Manchester University

Kloos, Maarten et al. 2012. Music, Space and Architecture. Amsterdam: Amsterdam Academy of Architecture

Laban, Rudolf. 1966. Choreutics. London: Macdonald and Evans

Moreno García-Mansilla, Luis, Luis Rojo de Castro y Emilio Tuñón Álvarez. 2005. Escritos circenses. Barcelona: Gustavo Gili

Muñoz Jiménez, María Teresa y Juan Antonio Cortés Vázquez de Parga. 1981. "La repetición en la arquitectura moderna/2". Arquitectura (COAM): 230

Owens, Craig. 1981. "The pro-scenic event". Art in America (December): 128-33

- 1994. Beyond recognition: Representation, power, and culture. Berkeley: University of California Press

Pallasmaa, Juhani. 2012. La mano que piensa: Sabiduría existencial y corporal en la arquitectura. Traducción de Moisés Puente. Barcelona: Gustavo Gili

Performing Arts Research and Training Studios. 2006. PARTS: Documenting ten years of contemporary dance education. Brussel: PARTS

Ramsay, Burt. 2006. Judson Dance Theater: Performative traces. New York: Routledge

Ross, Alex. 2009. El ruido eterno: Escuchar al siglo XX a través de su música. Traducción del inglés por Luis Gago. Barcelona: Seix Barral

Rushdie, Salman. 1991. "Is nothing sacred?" En Imaginary homelands: Essays and criticism 1981-1991. London: Granta

Tufte, Edward R. 2010. "Visual explanations: Images and quantities, evidence and narrative. Cheshire, CT: Graphics

1 "cronotopo", del griego "kronos" tiempo y "topos" lugar; Bajtin extrapola este concepto físico como la unidad espacio-tiempo indisoluble de carácter formal expresivo, que concebidos en vinculación con el movimiento y la materia, configuran sus propiedades y, así el tiempo puede ser una coordenada espacial: la cuarta dimensión del espacio. Su definición del cronotopo sería la conexión esencial de las relaciones temporales y espaciales asimiladas artísticamente (Bajtin 1989).

${ }^{2}$ http://www.rosas.be/en/production/partita-2 (De Keersmaeker 2013).

${ }^{3}$ citado en Kernay 1994.

${ }^{4}$ citada en Kästner 2007, p. 10.

${ }^{5}$ Dialógico: simultaneidad de enunciados en coexistencia (Bajtin 1981).

${ }^{6}$ Arquitectónica: Otra noción que aparece en su pensamiento es la "arquitectónica" como la fuerza estructuradora que organiza las relaciones comunicativas, ya sea entre yo y yo, entre yo y el otro, entre mismos distintos o entre yo y el mundo. Dicho de otra manera, el 
hecho de establecer conexiones entre los materiales diversos. En el caso que nos ocupa podría hablarse de la malla de interconexiones en el ámbito transdisciplinar. El studio de cómo se relacionan las distintas partes de un todo (Holoquist 1990, 149-50).

${ }^{7}$ citada en Kästner 2007, p. 8.

${ }^{8}$ Citado en en Corin et al. 2000.

${ }^{9}$ http://definicion.de/modulo/

${ }^{10}$ Definición RAE http://lema.rae.es/drae/?val=ritmo

(Artículo recibido 25-05-15; aceptado 24-06-15) 